\title{
ANÁLISE DO ENSINO DE VACINAÇÃO NO CURSO DE GRADUAÇÃO EM ENFERMAGEM *
}

\author{
Emiko Yoshikawa Egry**
}

EGRY, E. Y. Análise do ensino de vacinação no Curso de Graduação em Enfermagem. Rev. Esc. Enf. USP, São Paulo, 14(2):133-137, 1980.

Analisa-se o conteúdo programático do ensino de vacinação no Curso de Graduação em Enfermagem e Obstetrícia da Escola de Enfermagem da Universidade de São Paulo. Em seguida são relacionados os principais problemas encontrados durante o ensino da matéria $e$ dadas sugestões visando maior objetividade do ensino e maior aproveitamento e satisfação por parte dos alunos.

\section{INTRODUÇÃO}

O ensino de graduação na Escola de Enfermagem da Universidade de São Paulo faz, atualmente, parte do conteúdo programático da disciplina Enfermagem Preventiva e Comunitária, cuja duração teórico-prática é de 120 horas. Esta disciplina é ministrada no $7 .^{\circ}$ ou $8 .^{\circ}$ semestre do curso e, portanto, os alunos já a relacionam com seus conhecimentos de microbiologia, farmacologia, anatomia, fisiologia, fundamentos de enfermagem, enfermagem pediátrica, enfermagem em doenças transmissiveis, etc.

A parte da disciplina destinada exclusivamente à vacinação é pequena, constituindo cerca de 12 horas teóricas e de 8 a 12 horas práticas. Durante o estágio, correspondentes às outras partes da disciplina, o aluno orienta pais e responsáveis pelas crianças sobre os assuntos pertinentes à matéria.

\section{CONTEÚDO DO PROGRAMA DE VACINAÇÃO}

$\mathrm{O}$ conteúdo deste programa, resumidamente, refere-se a:

1. Cuidados gerais:

- precauções antes e após a aplicação das vacinas;

- contra-indicações gerais das vacinas;

- conservação das vacinas e

- material e condiçóes para o funcionamento de uma sala de vacinação.

2. Dados relativos a cada vacina, incluindo:

- tipo do produto;

* Trabalho apresentado no Painel "Imunizações: vacinação, programas e dificuldades operacionais". 1.० Encontro de Enfermeiras de Doenças Transmissíveis. Jornada de Enfermagem em Doenças Transmissíveis "Ano Internacional da Criança". Promovido pela Associação Brasileira de Enfermagem Seçāo de São Paulo.

* Professor Assistente das disciplinas Enfermagem Preventiva e Comunitária e Saúde da Comunidade da EEUSP. 
_ tipo de imunidade;

— idade para a vacinação;

_ doses e intervalo para a vacinação (básica e de reforço);

- contra-indicações específicas;

- cuidados especificos;

— técnica de aplicação e

- orientações de enfermagem.

Cabe ainda referir, em relação a este tópico, que é dada maior ênfase nas vacinas que são rotineiramente administradas nos Centros de Saúde da Secretaria de Estado da Saúde do Governo do Estado de São Paulo, por ser campo usual de estágio dos alunos da nossa Escola. As outras vacinas que não estão incluidas nesses programas rotineiros são, em geral, abordadas de maneira mais suscinta, a não ser em casos de epidemia, quando uma determinada vacina não de rotina é administrada (Ex. meningite).

3. Esquema de vacinação.

São abordados, neste tópico, os critérios de seleção de prioridades para a formulação do esquema, bem como o calendário vigente de vacinações da referida Secretaria.

4. Caderneta de vacinação.

Procura-se enfatizar não somente as normas de utilização da caderneta de vacinação, como também o modo de preenchê-la e os cuidados relativos à sua conservação

\section{PROBLEMAS ENCONTRADOS DURANTE O ENSINO DA MATÉRIA}

Os principais problemas encontrados durante o ensino da matéria serão a seguir enumerados, juntamente com as sugestões propostas para minimizá-los.

\section{PROBLEMAS}

SUGESTÕES

1. Cisão no ensino da matéria.

Os aspectos curativos das doenças transmissiveis e os cuidados de enfer. magem aos doentes são abordados na disciplina Enfermagem em Doenças Transmissiveis e os aspectos preventivos são abordados na disciplina Enfermagem Preventiva e Comunitária, não havendo integração entre elas. Isto
Integrar o ensino destas disciplinas visando oferecer aos alunos aspectos globais dos cuidados de enfermagem. 
acarreta o descontentamento por parte dos alunos e docentes, bem como, uma assistência incompleta aos clientes e pacientes.

2. Informações contraditórias encontradas em diferentes fontes bibliográficas.

As diversas fontes bibliográficas nem sempre coincidem nas recomendações sobre a aplicação das vacinas e os cuidados com as mesmas. A eleição da fonte bibliográfica a ser seguida nem sempre é fácil, o que acarreta problemas operacionais Ex.: A OMS constatou, por meio de pesquisa, que não existe interferência da ingestão de leite materno em horário próximo à administração da vacina Sabin, para a formação de anticorpos. Porém a Secretaria de Estado da Saúde continua recomendando que se mantenha um intervalo entre a mamada e a aplicação da vacina Sabin.

3. Insegurança dos alunos na execução de técnicas (injeção e medição por via oral) por falta de adestramento, acarretando demora no atendimento do cliente.
Pesquisar os assuntos controvertidos e publicar os resultados, a fim de que possam ser seguidas as mesmas orientações.

\begin{abstract}
Dar maior oportunidade em todas as disciplinas do curso de graduação para que o aluno desenvolva a habilidade manual principalmente quando se trata de cuidados com crianças, pois na aplicação de vacinas nelas reside a maior dificuldade.
\end{abstract}

Promover a integração docente assistencial o mais breve possivel.
4. Dificuldade na supervisão dos alunos não só por ser reduzido o tempo destinado a esta atividade, como também, pelo número insuficiente de docentes.
5. Inexistência de recursos materiais e financeiros para a realização de pesquisas nesta área dentro da Escola de Enfermagem da USP. As pesquisas, em geral, são subvencionadas pelos próprios docentes.
Promover a dotação de recursos financeiros para pesquisa. 
6. Divergência nas orientações recebidas pelos alunos e pelos funcionários do campo de estágio, o que gera conflito entre os mesmos, e também insegurança no cliente. Ex. Na triagem dos clientes para vacinação o aluno é orientado a verificar a temperatura de todas as crianças, mas o funcionário verifica somente daquelas que apresentam queixa de febre.
7. Falha nas técnicas de conservação e esteriliazção do material nos Centros de Saúde. Ex. Utilização de seringas e agulhas úmidas e uso de agulhas rombudas.
Promover entrosamento com enfermeiras do campo de estágio para troca de experiências e uniformidade nas orientações.
8. Falta de normas para conservação de vacinas à temperatura ambiente. Ex. Em caso de falta de energia elétrica, bastante comum em São Paulo, as vacinas ou são desprezadas ou são utiliza. das como válidas; não há qualquer norma sobre $o$ assunto para o pessoal nele se basear.
Verificar a possibilidade financeira de substituir o atual material por outro descartável; supervisão contínua dos funcionários por parte das enfermeiras de campo.

\section{CONCLUSÃO}

Concluindo, o ensino de imunização no curso de graduação em enfermagem deve ser melhorado pois:

- as doenças transmissíveis constituem, ainda, problema de âmbito nacional e regional e muitas delas podem ser prevenidas por meio de vacinas;

- as falhas ou erros na triagem, aplicação e orientação pós vacinais sempre acarretam danos ao cliente, os quais podem assumir maiores proporções de acordo com o erro;

- o enfermeiro desempenha importante papel na orientação do público a respeito de prevenção de doenças transmissíveis, em qualquer local onde ele trabalha.

Para que se melhore o ensino de vacinação nesta Escola é necessário que:

- haja integração efetiva entre as disciplinas de Enfermagem em Doenças Transmissiveis e Enfermagem Preventiva e Comunitária, bem como entre os docentes e os enfermeiros dos campos de estágio; 
- sejam realizadas pesquisas sobre o assunto, para as quais é necessário que haja recursos financeiros e materiais.

EGRY, E. Y. Teaching of immunization in undergraduate nursing programs. Rev. Esc. Enf. USP, São Paulo, 14(2):133-137, 1980.

The teaching of immunization to undergraduate stands of the University of São Paulo School of Nursing is analysed. The problems found are reported and suggestions are made for improving it. 